\title{
The advantage of surgical revascularization in diabetic patients @ check for updates with multivessel disease: More arterial conduits, more benefit
}

\author{
Rami Akhrass, MD, and Faisal G. Bakaeen, MD
}

Diabetes mellitus (DM) in North America is a national health crisis, expected to affect 36 million people in the United States alone in 2030, almost twice as many than in 2010. ${ }^{1}$ Patients with established coronary artery disease (CAD) who also have DM carry a worse prognosis compared with patients without DM. ${ }^{2}$ In addition, CAD accounts for up to $75 \%$ of deaths in diabetic patients, and more than $30 \%$ of patients presenting with an acute coronary syndrome have DM.

Diabetic patients have constituted approximately $40 \%$ of patients undergoing coronary artery bypass grafting (CABG) since the 2000 s, compared with only $7 \%$ in the 1970s. ${ }^{4}$ After surgery, patients with DM have worse shortand long-term survivals, in addition to increased immediate postoperative complications such as stroke, renal failure, wound infection, and length of stay. ${ }^{4} \mathrm{DM}$ is associated with more rapid progression of disease in saphenous vein grafts and in grafted and nongrafted native coronary arteries. ${ }^{5,6}$

The evidence is fairly robust with regard to the superiority of CABG over percutaneous coronary intervention (PCI) in patients with DM and multivessel disease (MVD) ${ }^{7-11} \mathrm{As}$ to the choice of the CABG conduits, in this patient cohort, there are data to suggest long-term benefits of multiarterial grafting (MAG) strategies, primarily based on large observational studies. ${ }^{12-15}$

This review will delineate the pathophysiology and anatomy of CAD in patients with DM, examine the available literature comparing $\mathrm{CABG}$ with $\mathrm{PCI}$, and discuss the role of MAG in this patient population.

\section{PATHOPHYSIOLOGY AND ANATOMY: WHY CORONARY ARTERY BYPASS GRAFTING MAKES SENSE}

Diabetic atherosclerosis is complex and mainly involves abnormalities in endothelial and vascular smooth muscle cell function. These have been attributed to various metabolic abnormalities, such as hyperglycemia, insulin resistance, and elevated free fatty acid liberation, which contribute to systemic reduction in the bioavailability of nitric oxide and increased oxidative stress. ${ }^{16}$

\footnotetext{
From the Coronary Revascularization Center, Department of Thoracic and Cardiovascular Surgery, Heart, Vascular and Thoracic Institute, Cleveland Clinic, Cleveland, Ohio. Disclosures: Authors have nothing to disclose with regard to commercial support. Received for publication Nov 22, 2020; revisions received Dec 24, 2020; accepted for publication Jan 6, 2021; available ahead of print Feb 27, 2021.

Address for reprints: Faisal G. Bakaeen, MD, Department of Thoracic and Cardiovascular Surgery, Heart, Vascular and Thoracic Institute, 9500 Euclid Ave, Cleveland, Ohio 44195 (E-mail: Bakaeef@ccf.org).

J Thorac Cardiovasc Surg 2022;164:119-22 $0022-5223 / \$ 36.00$

Copyright (c) 2021 by The American Association for Thoracic Surgery https://doi.org/10.1016/j.jtcvs.2021.01.140
}

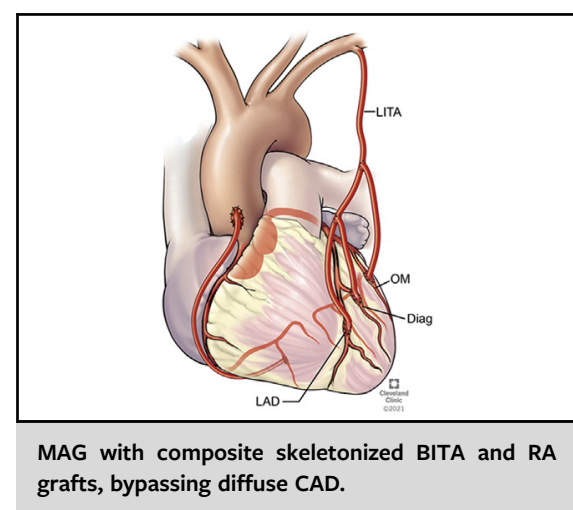

CENTRAL MESSAGE

MAG in appropriately selected patients with DM and multivessel CAD is associated with improved long-term outcomes.

This Invited Expert Opinion provides a perspec tive on the following paper: J Am Coll Cardiol. 2020 Jan 28;75(3):258-268 j.jacc.2019.11.026

See Commentaries on pages 123 and 125 .

Studies have consistently shown greater plaque burden, inflammatory content, and calcification in diabetic individuals compared with nondiabetic individuals. ${ }^{16}$ Diabetes causes more diffuse coronary disease with a 2-fold higher rate of total occlusions, making PCI difficult if not impossible and surgical revascularization technically more challenging.

Diabetes negatively affects the outcomes of both PCI and CABG. Numerous studies have shown that the risk of stent restenosis is doubled in patients with DM compared with patients without DM, placing them at higher risk for myocardial infarctions and need for repeat revascularizations. ${ }^{17,18}$ The diffuse disease and diminished runoff associated with diabetes are known to negatively affect graft patency rates. ${ }^{19}$ Therefore, it is not surprising that insulin-dependent DM was found to affect perioperative outcomes ${ }^{20}$ and to be one of the predictors of long-term survival after CABG (ASCERT study). ${ }^{21}$

Diabetic patients with CAD are more prone to develop progressive atherosclerotic plaque in the coronary beds. ${ }^{16} \mathrm{PCI}$ typically addresses the critical flow-limiting lesion, but disease progression in nontreated segments after PCI is an important cause of major adverse cardiovascular events (MACCEs), 
providing a rationale for the difference in results observed with short- versus longer-term ( $>5$ years) follow-up studies comparing PCI with CABG. ${ }^{22,23}$

Most clinically important obstructive lesions occur within the proximal $6 \mathrm{~cm}$ of coronary arteries, a distance typically bypassed in a CABG operation. ${ }^{22,24}$ Surgical revascularization protects against progression of native coronary atherosclerosis and de novo lesions by providing unhindered blood flow to the more distal coronary segments that are less likely to be diseased. Thus, CABG provides "surgical collateralization" that can improve survival by preventing future myocardial infarctions. ${ }^{25}$ This explains the consistent CABG advantage over PCI in patients with MVD and particularly diabetic patients with heavy atherosclerotic burden.

The durability of CABG is determined by long-term graft patency. Vein graft atherosclerosis is usually responsible for late graft failure and is the Achilles' heel of CABG surgery. On the other hand, the internal thoracic artery (ITA) is rarely affected by atherosclerosis because of its unique biological properties, such as increased nitric oxide levels that may also have a protective effect on native coronary circulation. ${ }^{26-29}$ Although not as resistant to atherosclerosis as ITAs, radial conduits are better than vein grafts and may be associated with similar outcomes to the use of right ITA grafts when supplementing a left ITA to left anterior descending (LAD) artery, even in diabetic patients. ${ }^{12,30}$

\section{COMPARATIVE STUDIES OF \\ REVASCULARIZATION STRATEGIES}

Multiple randomized controlled trials (RCTs) have demonstrated the superiority of CABG over PCI in the treatment of MVD associated with DM..$^{8-11,31}$ The bypass Angioplasty Revascularization Investigation (BARI 1) trial prospectively randomized patients with MVD to PCI or CABG. Although only $82 \%$ of patients received an ITA graft, the subgroup with DM had a significantly better 5year survival with surgery compared with PCI. ${ }^{8}$

The BARI 2 trial randomized patients with both CAD and DM to undergo intense medical therapy alone or with a revascularization strategy (CABG or PCI). A significant finding was MACCE reduction with surgery compared with medical therapy, a finding not seen among those who were selected to undergo PCI. ${ }^{9}$ The lack of the anticipated surgical survival advantage in this study can perhaps be explained, at least in part, by less than optimal use of even a single ITA conduit, in addition to the high prevalence of off-pump cases $(36 \%)$ with its reported higher rates of incomplete revascularization and lower patency graft rates. ${ }^{32}$ Other contributing factors include the intermediate follow-up period of an average 5 years, because the survival benefit from surgery is typically seen in the second decade after the index operation. ${ }^{33-35}$

Insights from the Arterial Revascularization Therapy Study (ARTS) trial on the impact of DM on PCI and surgical treatment of MVD noted that DM was a strong risk factor for the occurrence of MACCE in the population assigned to PCI but not in the CABG group. ${ }^{31}$ Likewise, the subgroup analysis of diabetic patients with MVD in the SYNTAX trial revealed a significantly higher rate of cardiac deaths of approximately 3 times in the PCI group compared with the CABG cohort. ${ }^{36}$ Furthermore, a post hoc analysis at 10 years, the Medicine Angioplasty Surgery Study (MASS) II, was conducted of the randomized prospective MASS I trial that compared medical treatment, CABG, and PCI. In the entire surgical group including diabetic patients and nondiabetic patients, $41 \%$ received 2 ITAs or radial arteries (RAs); however, $6 \%$ received no arterial grafts. Among diabetic patients with MVD, a statistically significant difference was noted in the cardiac mortality rate favoring $\mathrm{CABG}{ }^{37}$

The Future Revascularization Evaluation in Patients with Diabetes Mellitus: Optimal Management of Multi-vessel Disease (FREEDOM) trial was the first adequately powered randomized study, in diabetic patients with MVD, to compare CABG with PCI using drug-eluding stents. The FREEDOM follow-up study showed that in patients with DM and MVD, CABG was associated with improved long-term survival and reduction in MACCE at 8 years compared with PCI and drug-eluting stents. ${ }^{10,11}$ In this trial, $94.4 \%$ had a left ITA, $12.3 \%$ had bilateral ITA (BITA), and $6.4 \%$ had left ITA with RA grafts.

Beyond the narrow and selected population of an RCT, a large observational review of real-world practice of patients presenting with an acute coronary syndrome showed that CABG had a $52 \%$ long-term mortality reduction and $37 \%$ superiority in terms of MACCE outcomes over PCI. ${ }^{38}$ Likewise, Takagi and colleagues ${ }^{39}$ reported the outcomes of more than 8000 patients with DM and MVD in a propensity score-matching analysis. They noted that CABG was associated with improved long-term mortality and freedom from MACCE compared with PCI. The cumulative incidence of myocardial infarction was $16.4 \%$ among those who received PCI compared with $7.2 \%$ in patients who underwent $\mathrm{CABG}$, and repeat revascularization was greater than 3 -fold in the PCI group ( $25.9 \%$ vs $7.8 \%$ ). Of note, $82 \%$ in the surgical cohort received 3 or more grafts compared with only $4.6 \%$ in the PCI group who had 3 or more vessels stented, which is a reflection of the superior ability of CABG in attaining the important goal of complete revascularization. ${ }^{39}$

The 2014 American Heart Association/American College of Cardiology guidelines for the revascularization of stable ischemic heart disease recommend that patients with diabetes and complex 3- or 2-vessel disease with proximal LAD artery involvement, who are good surgical candidates, should be treated with CABG (Class I, Level of Evidence: B). ${ }^{3}$ Similar recommendations were made in the 2018 guidelines of the European Society of Cardiology/European Association for Cardio-Thoracic Surgery in patients with DM and MVD, but with a higher level of 
evidence for CABG over PCI (Class I, Level of Evidence: A). ${ }^{40}$

The importance of arterial grafting in reaping an additional survival benefit in CABG cannot be overemphasized. In fact, the survival advantage in the BARI trial was most evident and pronounced in the surgical group subset who received an ITA graft. ${ }^{6,8}$ A recent meta-analysis of RCTs, comparing surgical revascularization with PCI in diabetic patients, found a $33 \%$ mortality reduction at 5 years with CABG, despite an arterial bypass use rate of at least 1 arterial conduit ranging from $88.5 \%$ to $97 \%$, which is lower than the bar of current standard of care set by the surgical community that approaches $100 \%$. It is likely that an even greater outcome advantage with $\mathrm{CABG}$ could have been realized with a more frequent use of arterial conduits. Except for the MASS II trial, with a reported MAG rate of $41 \%,{ }^{37}$ the majority of RCTs suffered from a low rate of MAG.

Multiple observational studies have documented that MAG improves survival and freedom from reinterventions. $^{34,35}$ The seminal study by Lytle and colleagues ${ }^{34}$ showed that 2 ITAs are better than 1, with decreased risk of deaths and reinterventions. The presence of DM was an incremental risk factor for worse outcomes. In the diabetic subpopulation, $11 \%$ received 2 ITA grafts compared with $13 \%$ in the nondiabetic patients, with a significant survival advantage when BITA was deployed as a surgical strategy. ${ }^{34}$ Chikwe and colleagues ${ }^{35}$ found that MAG was associated with decreased mortality and lower risk of myocardial infarctions and reinterventions in a large statewide registry, in which DM was present in $40 \%$ of patients. Furthermore, a large population-based study from British Columbia demonstrated a consistent benefit of MAG among diabetic patients, with a greater absolute mortality rate reduction at 15 years among diabetic patients compared with nondiabetic patients $(9.55 \%$ vs $3.8 \%))^{13}$

Puskas and colleagues ${ }^{14}$ noted that BITA grafting conferred a $35 \%$ mortality reduction at 8 years compared with single ITA use among patients with DM and MVD. ${ }^{14}$ In addition, in a 30-year follow-up study of propensitymatched cohorts, BITA grafting significantly enhanced survival with a median gain of 3.3 years and without increasing perioperative morbidity. ${ }^{15}$

RA use is also associated with a significant late survival advantage compared with saphenous vein graft use in diabetic patients ${ }^{12}$ and compares favorably with right ITA use. ${ }^{30}$ In general, regardless of whether a second ITA or an RA is used to supplement the left ITA to LAD, it is best to maximize the amount of myocardium supplied by the arterial grafts by using them in bypassing anatomically important targets. Such a strategy is associated with an incremental survival advantage. ${ }^{41}$

Multiple barriers have been implicated in the lack of widespread adoption of MAG, especially BITA use, but perhaps the most cited in diabetic patients is the concern for wound healing. ${ }^{42}$ ITA skeletonization has significantly reduced sternal wound complications and has become routine practice for many MAG surgeons. Skeletonization causes less disruption to sternal collateral blood flow by less cautery use and by dividing ITA branches closer to their origins. The increased risk of wound infections and other sternal complications, initially seen with BITA harvesting, can be mitigated with the adoption of the skeletonization technique even in patients with DM. ${ }^{43}$

The following points can be inferred regarding DM and CAD:

1. DM is on the rise and is strongly associated with diffuse MVD.

2. CAD is a major cause of death in diabetic patients.

3. DM is an independent risk factor for late cardiovascular mortality and is a marker for worse short- and long-term outcomes after percutaneous and surgical revascularization.

4. Compared with PCI, CABG provides more complete revascularization and can offer protection against future lesions regardless of the complexity of the coronary disease. The clinical translation is improved survival and freedom from MACCE observed with CABG.

5. MAG use is strongly encouraged because it can provide additional outcome advantage (including survival benefit) in diabetic patients with MVD undergoing surgical revascularization.

6. ITA skeletonization decreases wound complications in BITA CABG.

\section{CONCLUSIONS}

The risk of premature morbidity and mortality is increased in diabetic patients, with cardiovascular disease being the leading cause of death. A consistent finding among most studies is that diabetic patients with MVD benefit more from CABG compared with PCI. The longterm advantage of CABG can be enhanced with the judicious use of MAG strategies.

\section{Conflict of Interest Statement}

Disclosures: The authors reported no conflicts of interest.

The Journal policy requires editors and reviewers to disclose conflicts of interest and to decline handling or reviewing manuscripts for which they may have a conflict of interest. The editors and reviewers of this article have no conflicts of interest.

\section{References}

1. Shaw JE, Sicree RA, Zimmet PZ. Global estimates of the prevalence of diabetes for 2010 and 2030. Diabetes Res Clin Pract. 2010;87:4-14.

2. Hueb W, Gersh BJ, Costa F, Lopes N, Soares PR, Dutra P, et al. Impact of diabetes on five-year outcomes of patients with multivessel coronary artery disease. Ann Thorac Surg. 2007;83:93-9. 
3. Nishimura RA, Otto CM, Bonow RO, Ruiz CE, Skubas NJ, Sorajja P. 2014 AHA/ ACC guideline for the management of patients with non-ST-elevation acute coronary syndrome: a report of the American College of Cardiology/American Heart Association Task Force on Practice Guidelines. J Am Coll Cardiol. 2014;64:e139-228.

4. Raza S, Sabik JF, Ainkaran P, Blackstone EH. Coronary artery bypass grafting in diabetics: a growing health care cost crisis. J Thorac Cardiovasc Surg. 2015; 150: 304-12.e2.

5. Morris JJ, Smith LR, Jones RH, Glower DD, Morris PB, Muhlbaier LH, et al. Influence of diabetes and mammary artery grafting on survival after coronary bypass. Circulation. 1991;84:III275-83.

6. Narins SGE, Narins CR. Problem of angioplasty in diabetics. Circulation. 1997; 96:1707-10.

7. Verma S, Farkouh ME, Yanagawa B, Fitchett DH, Ahsan MR, Ruel M, et al. Comparison of coronary artery bypass surgery and percutaneous coronary intervention in patients with diabetes: a meta-analysis of randomised controlled trials. Lancet Diabetes Endocrinol. 2013;1:317-28.

8. (BARI) TBARI. Comparison of coronary bypass surgery with angioplasty in patients with multivessel disease. $N$ Engl J Med. 1996;335:217-25.

9. BARI 2D Study Group, Frye RL, August P, Brooks MM, Hardison RM, Kelsey SF, MacGregor JM, et al. A randomized trial of therapies for type 2 diabetes and coronary artery disease. N Engl J Med. 2009;360:2503-15.

10. Farkouh ME, Domanski M, Sleeper LA, Siami FS, Dangas G, Mack M, et al. Strategies for multivessel revascularization in patients with diabetes. $N$ Engl J Med. 2012;367:2375-84.

11. Farkouh ME, Domanski M, Dangas GD, Godoy LC, Mack MJ, Siami FS, et al. Long-term survival following multivessel revascularization in patients with diabetes: the FREEDOM Follow-On Study. J Am Coll Cardiol. 2019;73:629-38.

12. Schwann TA, Al[HYPHEN]Shaar L, Engoren M, Habib RH. Late effects of radial artery vs saphenous vein grafting for multivessel coronary bypass surgery in diabetics: a propensity-matched analysis. Eur J Cardiothorac Surg. 2013;44:701-10.

13. Pu A, Ding L, Shin J, Price J, Skarsgard P, Wong DR, et al. Long-term outcomes of multiple arterial coronary artery bypass grafting: a population-based study of patients in British Columbia, Canada. JAMA Cardiol. 2017;2:1187-96.

14. Puskas JD, Sadiq A, Vassiliades TA, Kilgo PD, Lattouf OM. Bilateral internal thoracic artery grafting is associated with significantly improved long-term survival, even among diabetic patients. Ann Thorac Surg. 2012;94:710-6.

15. Dorman MJ, Kurlansky PA, Traad EA, Galbut DL, Zucker M, Ebra G. Bilateral internal mammary artery grafting enhances survival in diabetic patients: a 30-year follow-up of propensity score-matched cohorts. Circulation. 2012;126:2935-42.

16. Puri R, Kataoka Y, Uno K, Nicholls SJ. The distinctive nature of atherosclerotic vascular disease in diabetes: pathophysiological and morphological insights. Curr Diab Rep. 2012;12:280-5.

17. Daemen J, Wenaweser P, Tsuchida K, Abrecht L, Vaina S, Morger C, et al. Early and late coronary stent thrombosis of sirolimus-eluting and paclitaxel-eluting stents in routine clinical practice: data from a large two-institutional cohort study Lancet. 2007;369:667-78.

18. Machecourt J, Danchin N, Lablanche JM, Fauvel JM, Bonnet JL, Marliere S, et al. Risk factors for stent thrombosis after implantation of sirolimus-eluting stents in diabetic and nondiabetic patients. The EVASTENT Matched-Cohort Registry. J Am Coll Cardiol. 2007;50:501-8.

19. Ledru F, Ducimetière P, Battaglia S, Courbon D, Beverelli F, Guize L, Guermonprez JL, Diébold B. New diagnostic criteria for diabetes and coronary artery disease: Insights from an angiographic study. J Am Coll Cardiol. 2001;37:1543-50.

20. Shahian DM, O'Brien SM, Filardo G, Ferraris VA, Haan CK, Rich JB, et al. The Society of Thoracic Surgeons 2008 Cardiac Surgery Risk Models: part 1coronary artery bypass grafting surgery. Ann Thorac Surg. 2009;88:S2-22.

21. Shahian DM, O'Brien SM, Sheng S, Grover FL, Mayer JE, Jacobs JP, et al. Predictors of long-term survival after coronary artery bypass grafting surgery: results from the society of thoracic surgeons adult cardiac surgery database (The ASCERT Study). Circulation. 2012;125:1491-500.

22. Kuntz RE. Importance of considering atherosclerosis progression when choosing a coronary revascularization strategy: the diabetes-percutaneous transluminal coronary angioplasty dilemma. Circulation. 1999;99:847-51.

23. Rozenman Y, Sapoznikov D, Mosseri M, Gilon D, Lotan C, Nassar H, et al. Longterm angiographic follow-up of coronary balloon angioplasty in patients with diabetes mellitus: a clue to the explanation of the results of the BARI study. Balloon Angioplasty Revascularization Investigation. J Am Coll Cardiol. 1997;30:1420-5.

24. Strong JP, Eggen DA, Oalmann NC. The natural history, geographic pathology, and epidemiology of atherosclerosis. In: Wissler RW, Geer JC, eds. The Pathogenesis of Atherosclerosis. Baltimore, MD: Williams \& Wilkins; 1972:20.
25. Doenst T, Haverich A, Serruys P, Bonow RO, Kappetein P, Falk V, et al. PCI and CABG for treating stable coronary artery disease. J Am Coll Cardiol. 2019;73: 964-76.

26. Thourani VH, Weintraub WS, Stein B, Gebhart SSP, Craver JM, Jones EL, et al. Influence of diabetes mellitus on early and late outcome after coronary artery bypass grafting. Ann Thorac Surg. 1999;67:1045-52.

27. Huszka M, Kaplar M, Rejto L, Tornai I, Palatka K, Laszlo P, et al. The association of reduced endothelium derived relaxing factor-no production with endothelial damage and increased in vivo platelet activation in patients with diabetes mellitus. Thromb Res. 1997;86:173-80.

28. Dimitrova KR, Hoffman DM, Geller CM, Dincheva G, Ko W, Tranbaugh RF. Arterial grafts protect the native coronary vessels from atherosclerotic disease progression. Ann Thorac Surg. 2012;94:475-81.

29. Broeders MAW, Doevendans PA, Maessen JG, Van Gorsel E, Oude Egbrink MGA, Daemen MJAP, et al. The human internal thoracic artery releases more nitric oxide in response to vascular endothelial growth factor than the human saphenous vein. J Thorac Cardiovasc Surg. 2001;122:305-9.

30. Raza S, Blackstone EH, Houghtaling PL, Koprivanac M, Ravichandren K, Javadikasgari $\mathrm{H}$, et al. Similar outcomes in diabetes patients after coronary artery bypass grafting with single internal thoracic artery plus radial artery grafting and bilateral internal thoracic artery grafting. Ann Thorac Surg. 2017;104:1923-32.

31. Abizaid A, Costa MA, Centemero M, Abizaid AS, Legrand VMG, Limet RV, et al. Clinical and economic impact of diabetes mellitus on percutaneous and surgical treatment of multivessel coronary disease patients: insights from the arterial revascularization therapy study (ARTS) trial. Circulation. 2001;104:533-8.

32. Hattler B, Messenger JC, Shroyer AL, Collins JF, Haugen SJ, Garcia JA, et al. Offpump coronary artery bypass surgery is associated with worse arterial and saphenous vein graft patency and less effective revascularization: results from the Veterans Affairs Randomized On/Off Bypass (ROOBY) trial. Circulation. 2012;125:2827-35.

33. Loop FD, Lytle BW, Cosgrove DM, Stewart RW, Goormastic M, Williams GW Influence of the internal-mammary-artery graft on 10-year survival and other cardiac events. $N$ Engl J Med. 1986;314:1-6.

34. Lytle BW, Blackstone EH, Loop FD, Houghtaling PL, Arnold JH, Akhrass R, et al. Two internal thoracic artery grafts are better than one. J Thorac Cardiovasc Surg. 1999;117:855-72.

35. Chikwe J, Sun E, Hannan EL, Itagaki S, Lee T, Adams DH, et al. Outcomes of second arterial conduits in patients undergoing multivessel coronary artery bypass graft surgery. J Am Coll Cardiol. 2019;74:2238-48.

36. Kappetein AP, Head SJ, Morice MC, Banning AP, Serruys PW, Mohr FW, et al. Treatment of complex coronary artery disease in patients with diabetes: 5-year results comparing outcomes of bypass surgery and percutaneous coronary intervention in the syntax trial. Eur J Cardiothorac Surg. 2013;43:1006-13.

37. Lima EG, Hueb W, Garcia RMR, Pereira AC, Soares PR, Favarato D, et al. Impact of diabetes on 10-year outcomes of patients with multivessel coronary artery disease in the Medicine, Angioplasty, or Surgery Study II (MASS II) trial. Am Heart J. 2013;166:250-7.

38. Ramanathan K, Abel JG, Park JE, Fung A, Mathew V, Taylor CM, et al. Surgical versus percutaneous coronary revascularization in patients with diabetes and acute coronary syndromes. J Am Coll Cardiol. 2017;70:2995-3006.

39. Takagi H, Watanabe T, Mizuno Y, Kawai N, Umemoto T. A meta-analysis of adjusted risk estimates for survival from observational studies of complete versus incomplete revascularization in patients with multivessel disease undergoing coronary artery bypass grafting. Interact Cardiovasc Thorac Surg. 2014;18: 679-82.

40. Sousa-Uva M, Neumann FJ, Ahlsson A, Alfonso F, Banning AP, Benedetto U, et al. 2018 ESC/EACTS Guidelines on myocardial revascularization. Eur J Cardiothorac Surg. 2019;55:4-90.

41. Bakaeen FG, Ravichandren K, Blackstone EH, Houghtaling PL, Soltesz EG, Johnston DR, et al. Coronary artery target selection and survival after bilateral internal thoracic artery grafting. J Am Coll Cardiol. 2020;75:258-68.

42. Bakaeen FG. Harvesting arterial grafts: barebones or more. Semin Thorac Cardiovasc Surg. 2015;27:121-2.

43. Benedetto U, Altman DG, Gerry S, Gray A, Lees B, Pawlaczyk R, et al. Pedicled and skeletonized single and bilateral internal thoracic artery grafts and the incidence of sternal wound complications: insights from the Arterial Revascularization Trial. J Thorac Cardiovasc Surg. 2016;152:270-6.

Key Words: coronary artery bypass grafting, coronary artery disease, diabetes mellitus, internal thoracic artery, multiarterial grafting, percutaneous intervention 